\title{
Primary percutaneous coronary intervention is appropriate in transient ST-elevation myocardial infarction
}

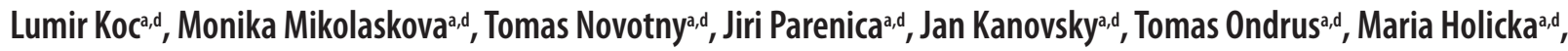 \\ Martin Poloczek ${ }^{a}$, Jiri Jarkovsky ${ }^{b, d}$, Marek Malik, ${ }^{c, d}$, Petr Kala ${ }^{a, d}$
}

\begin{abstract}
Introduction. Reperfusion therapy by primary percutaneous coronary intervention (PPCI) is generally indicated in patients suffering from acute myocardial infarction (MI) with ST-segment elevation (STEMI). Prior to hospital admission, full ST-segment resolution (fSTR) may occur. Optimal management of such patients with transient STEMI (TSTEMI) is potentially challenging. Our aim was to evaluate the hypothesis that in TSTEMI patients, patency of infarct related artery (IRA) is achieved before PPCl, and to compare the outcome of TSTEMI and STEMI patients during a prolonged follow-up. Material and Methods. Three hundred consecutive adult STEMI patients were referred to catheterization laboratory. In all patients, standard 12 lead ECGs were obtained both at the time of the first medical contact, and on catheterization laboratory admission.

Results. TSTEMI occurred in 20 patients (6.7\%). Despite fSTR (isoelectric ST segment), occluded IRA was found in 5 of these patients (25\%). Pre-PPCI TIMI flow grade 2 was found in 6 TSTEMI patients (30\%). Troponin T value at $24 \mathrm{~h}$ after symptom onset was lower in the TSTEMI group $(1.8 \pm 2.5 \mathrm{mg} / \mathrm{L}$ vs. $3.6 \pm 3.5 \mathrm{mg} / \mathrm{L}, P=0.008)$. These patients also had a lower value of brain natriuretic peptide $(156.3 \pm 119.5 \mathrm{ng} / \mathrm{L}$ vs. $438.5 \pm 429.0 \mathrm{ng} / \mathrm{L}, P<0.001)$ and higher left ventricular ejection fraction $(59.9 \pm 6.3 \%$ vs. $51.6 \pm 10.2 \%, P<0.001)$. All patients were followed for a median of 5.6 years during which the overall survival did not differ between the TSTEMI and STEMI groups.

Conclusion. Primary PCI is strongly recommended in TSTEMI patients because of a relatively high incidence of occluded infarct related arteries. The rate of patients with TSTEMI is relatively low.
\end{abstract}

Key words: STEMI, Primary PCI, ST-segment resolution, TSTEMI, 5-year survival

Received: November 1, 2020; Revised: December 22, 2020; Accepted: January 8, 2021; Available online: February 4, 2021 https://doi.org/10.5507/bp.2021.005

(c) 2022 The Authors; https://creativecommons.org/licenses/by/4.0/

${ }^{a}$ Department of Internal Medicine and Cardiology, University Hospital Brno, Czech Republic

'Institute of Biostatistics and Analyses, Masaryk University, Brno, Czech Republic

'National Heart and Lung Institute, Imperial College of London, London, United Kingdom

${ }^{d}$ Faculty of Medicine, Masaryk University, Brno, Czech Republic

Corresponding author: Petr Kala, e-mail: kala.petr@fnbrno.cz

\section{INTRODUCTION}

The initial field diagnosis of acute myocardial infarction (AMI) is based on the presence of ischemia symptoms combined with representative ECG changes ${ }^{1}$. Patients with ST-segment elevations AMI (STEMI) are well known to benefit from early reperfusion therapy. Whenever available, emergent primary percutaneous coronary intervention (PPCI) is superior to thrombolysis. It leads to optimal coronary flow restoration ${ }^{2,3}$, reduces myocardial necrosis ${ }^{4}$, lowers in-hospital mortality ${ }^{5}$, decreases the reinfarction risk $^{6}$, and improves prognosis ${ }^{5,7,8}$.

The ST segment elevation is a valuable indicator of ongoing myocardial ischemia ${ }^{9}$. The absence of ST segment resolution has repeatedly been associated with greater extent of myocardial damage, higher re-infarction rates, and increased mortality ${ }^{10-13}$. However, during the transport to catheterization laboratory, full resolution of ST-segment (fSTR) up to the isoelectric line may occur prior to PPCI initiation. For this condition, the term transient STEMI (TSTEMI) has been proposed ${ }^{14}$. The optimal management of TSTEMI patients has not been established and there are speculations on the benefit-risk ratio of PPCI in these patients.

The aim of our study was to evaluate the hypothesis that in TSTEMI patients, patency of infarct related artery (IRA) and full restoration of coronary blood flow is achieved before PPCI. We also compared the outcome of STEMI and TSTEMI patients during a prolonged follow-up.

\section{MATERIAL AND METHODS}

Between December 2012 and April 2015, the study prospectively enrolled 300 consecutive STEMI patients (107 females) fulfilling the criteria for PPCI according to the present guidelines ${ }^{1}$. Shortly after enrolment, one male patient withdrew his consent. Thus, 299 patients constituted the study population. The study protocol was approved by the local Ethics Committee and all patients gave signed informed consent according to the Helsinki Declaration. 
After the field diagnosis of STEMI, all patients were transported directly to the catheterization laboratory for PPCI. Patients were excluded if in cardiogenic shock, if unconscious on hospital admission, or if unable or unwilling to provide signed informed consent. The initial ECGs were obtained either in the ambulance or at the referring hospital. Subsequent ECGs were obtained immediately on arrival to the catheterization laboratory shortly before PPCI procedures were initiated.

The STEMI was considered transient if no residual ST-elevations were present on admission to the catheterization laboratory. All ECGs were analysed by two independent cardiologists blinded to clinical characteristics and endpoints. In the rare cases of disagreement, a third senior cardiologist provided the final ECG diagnosis.

The unfractionated heparin, acetylsalicylic acid, and intravenous opioids were administered by the first medical contact immediately after the STEMI diagnosis. Inhibitors of ADP receptors $\mathrm{P}_{2} \mathrm{Y}_{12}$ were administered during catheterization. At the discretion of the operators and according to the guidelines ${ }^{15}$, glycoprotein IIb/IIIa inhibitors were used as a bailout therapy during catheterization.

The coronary flow in the infarct related artery (IRA) was classified by the operator according to the TIMI classification ${ }^{16}$ both before and after PPCI. Prior to PPCI, IRA was classified as occluded and patent if with TIMI flow grade $0 / 1$ and $2 / 3$, respectively. Successful revascularisation was defined as a TIMI flow 2/3 after PPCI and the absence of no-reflow phenomenon.

The time to reperfusion therapy was defined as the time-interval between symptom onset and the wire passage in the culprit artery. MI localization was classified as anterior and inferior if ST elevations predominantly occurred in leads $\mathrm{V}_{1}-\mathrm{V}_{4}$ and in leads II, III, aVF, respectively. "Other" MI localization was considered with ST elevations predominantly in leads $\mathrm{I}$, aVL and/or $\mathrm{V}_{5}, \mathrm{~V}_{6}$ or with isolated ST depressions in leads $\mathrm{V}_{1}-\mathrm{V}_{4}$.

The extent of myocardial infarction was identified according to the serum levels of troponin $\mathrm{T}$, brain natriuretic peptide (BNP) and the left ventricular ejection fraction (LVEF). Troponin T and BNP was analysed 24 hours after chest pain onset and assessed using high sensitivity method of electric chemiluminescent microparticle immunoassay Cobas 8000 (Roche Diagnostics). BNP was assessed using chemiluminescent microparticle immunoassay test, analysator Architect i1000, (Abbot Diagnostics). LVEF was assessed by transthoracic echocardiography (Vivid 7, General Electric Healthcare) using Simpson's formula 3 to 5 days after the index MI. The presence of heart failure during the acute phase of MI was defined according to Killip class classification ${ }^{17}$.

The primary study goal was to determine whether the TSTEMI patients present with full IRA patency. The secondary goal was to compare the extent of myocardial infarction in TSTEMI and STEMI patients as based on biomarkers and LVEF, and to compare the long-term survival of TSTEMI and STEMI patients. As an exploratory analysis, the survival of patients with pre-PPCI TIMI flow grade 3 was compared with the survival of others. All- cause mortality data were retrieved from a Nation-wide health insurance registry.

Continuous and categorical variables are presented as means \pm standard deviation and as absolute and relative frequencies. Group differences between categorical variables were evaluated by Fisher's exact test. Continuous variables were compared by two-sample t-tests. All-cause mortality comparisons were displayed using Kaplan-Meier survival curves and compared using the log-rank test. $P$ levels $<0.05$ were considered statistically significant. The statistical analyses were performed using SPSS package (IBM, Armonk, New York, USA) version 25.

\section{RESULTS}

TSTEMI occurred in 20 patients $(6.7 \%)$. Clinical characteristics of patients with TSTEMI and STEMI are summarized in Table 1. TSTEMI patients were younger but other main clinical characteristics were not different between groups. There were also no group differences in pre-admission antithrombotic therapy and during catheterization. Likewise, time delays to revascularization did not differ.

Importantly, despite isoelectric ST segment, occluded IRA was found in 5 (25\%) of the TSTEMI patients and pre-PPCI TIMI flow grade 2 was observed in 6 others (30\%). Hence, prior to PPCI intervention, only $45 \%$ of the TSTEMI patients showed complete coronary flow restoration.

The PPCI was successful in most patients. The prePPCI TIMI flow grades of $0,1,2$, and 3 were noted in 156, 27, 67, and 49 patients, respectively. After PPCI, these counts changed to 3, 0, 20, and 276, respectively. All TSTEMI patients had a TIMI flow grade 3 after the PPCI.

Lower serum levels of Troponin T and of BNP indicated lesser extent of myocardial necrosis in TSTEMI patients who also had higher LVEF values. The occurrence of heart failure did not differ between study groups. The overall survival over a median of 5.6 years was not statistically different between TSTEMI and STEMI patients (Fig. 1). However, there was a near significant trend to lower mortality in patients with pre-PPCI TIMI flow grade 3 compared to others (Fig. 2).

\section{DISCUSSION}

In our study, TSTEMI occurred in $6.7 \%$ of patients but only a minority of these patients showed complete restoration of coronary flow prior to PPCI intervention.

STEMI-related myocardial ischemia is usually caused by atherosclerotic plaque rupture, subsequent thrombus formation and IRA occlusion ${ }^{18}$. Administration of antithrombotic therapy and endogenous regulatory mechanisms of the endothelium may consequently result in thrombus degradation, restoration of the IRA flow. Relief of myocardial ischemia results in fSTR and in TSTEMI presentation. 
Table 1. Comparison of clinical characteristics of TSTEMI and STEMI patients.

\begin{tabular}{|c|c|c|c|}
\hline Parameter & $\begin{array}{l}\text { TSTEMI } \\
(\mathrm{n}=20)\end{array}$ & $\begin{array}{c}\text { STEMI } \\
(\mathrm{n}=279)\end{array}$ & $P$ \\
\hline Male & $15(75.0 \%)$ & $177(63.4 \%)$ & 0.344 \\
\hline Age [years] & $56.5 \pm 11.2$ & $63.2 \pm 12.0$ & 0.021 \\
\hline $\mathrm{BMI}\left[\mathrm{kg} / \mathrm{m}^{2}\right]$ & $29.9 \pm 3.7$ & $28.4 \pm 4.6$ & 0.103 \\
\hline Admission serum creatinine $[\mu \mathrm{mol} / \mathrm{L}]$ & $86.9 \pm 17.1$ & $82.1 \pm 25.2$ & 0.254 \\
\hline \multicolumn{4}{|l|}{ History of } \\
\hline Myocardial infarction & $1(5.0 \%)$ & $27(9.7 \%)$ & 0.706 \\
\hline Hypertension & $11(55.0 \%)$ & $167(59.9 \%)$ & 0.814 \\
\hline Hypercholesterolemia & $15(75.0 \%)$ & $152(54.5 \%)$ & 0.102 \\
\hline Diabetes mellitus & $2(10.0 \%)$ & $64(22.9 \%)$ & 0.265 \\
\hline Stroke & $0(0.0 \%)$ & $12(4.3 \%)$ & 0.999 \\
\hline Smoking & $9(45.0 \%)$ & $127(45.5 \%)$ & 0.999 \\
\hline \multicolumn{4}{|l|}{ Previous medication with } \\
\hline Aspirin & $1(5.0 \%)$ & $43(15.4 \%)$ & 0.328 \\
\hline Clopidogrel & $1(5.0 \%)$ & $6(2.2 \%)$ & 0.387 \\
\hline B-blockers & $3(15.0 \%)$ & $67(24.0 \%)$ & 0.584 \\
\hline ACE/AT2 & $9(45.0 \%)$ & $120(43.0 \%)$ & 0.999 \\
\hline Statins & $4(20.0 \%)$ & $50(17.9 \%)$ & 0.767 \\
\hline \multicolumn{4}{|c|}{ Antithrombotic treatment before catheterization } \\
\hline Heparin & $20(100.0 \%)$ & $270(96.8 \%)$ & 0.999 \\
\hline Aspirin & $20(100.0 \%)$ & $258(92.5 \%)$ & 0.378 \\
\hline \multicolumn{4}{|c|}{ Antithrombotic treatment during catheterization } \\
\hline Clopidogrel & $5(25.0 \%)$ & $74(26.5 \%)$ & 0.999 \\
\hline Prasugrel & $8(40.0 \%)$ & $117(41.9 \%)$ & 0.999 \\
\hline Ticagrelor & $7(35.0 \%)$ & $58(20.8 \%)$ & 0.160 \\
\hline IIb/IIIa inhibitors & $5(25.0 \%)$ & $101(36.2 \%)$ & 0.347 \\
\hline \multicolumn{4}{|l|}{ MI localization } \\
\hline Anterior & $5(25.0 \%)$ & $125(44.8 \%)$ & 0.101 \\
\hline Inferior & $13(65.0 \%)$ & $134(48.0 \%)$ & 0.131 \\
\hline Other & $2(10.0 \%)$ & $20(7.2 \%)$ & 0.634 \\
\hline \multicolumn{4}{|l|}{ Infarct related artery } \\
\hline LAD/LM & $5(25.0 \%)$ & $128(45.9 \%)$ & 0.104 \\
\hline $\mathrm{LCx}$ & $6(30.0 \%)$ & $46(16.5 \%)$ & 0.168 \\
\hline RCA & $9(45.0 \%)$ & $105(37.6 \%)$ & 0.649 \\
\hline \multicolumn{4}{|l|}{ Acute heart failure } \\
\hline No (Killip I) & $17(85.0 \%)$ & $243(87.7 \%)$ & 0.724 \\
\hline Yes (Killip II+III) & $3(15.0 \%)$ & $34(12.3 \%)$ & \\
\hline \multicolumn{4}{|l|}{ Pre-PPCI TIMI flow } \\
\hline $0+1$ & $5(25 \%)$ & $178(64.0 \%)$ & 0.001 \\
\hline $2+3$ & $15(75 \%)$ & $101(36.0 \%)$ & \\
\hline \multicolumn{4}{|l|}{ Post-PPCI TIMI flow } \\
\hline $0+1$ & $0(0.0 \%)$ & $3(1.1 \%)$ & 0.999 \\
\hline $2+3$ & $17(100.0 \%)$ & $272(98.9 \%)$ & \\
\hline $\mathrm{BNP}[\mathrm{ng} / \mathrm{L}]$ & $156.3 \pm 119.5$ & $438.5 \pm 429.0$ & $<0.001$ \\
\hline Troponin T max. [mg/L] & $1.8 \pm 2.5$ & $3.6 \pm 3.5$ & 0.008 \\
\hline LVEF [\%] & $59.9 \pm 6.3$ & $51.6 \pm 10.2$ & $<0.001$ \\
\hline Time to reperfusion therapy [min] & $284.0 \pm 195.0$ & $294.9 \pm 242.8$ & 0.848 \\
\hline
\end{tabular}

BMI, Body Mass Index; ACE, angiotensin-converting enzyme inhibitor; AT2, angiotensin II blocker; LAD, Left anterior descending artery; LCx, Left circumflex artery; RCA, Right coronary artery; BNP, brain natriuretic peptide; LVEF, left ventricular ejection fraction 


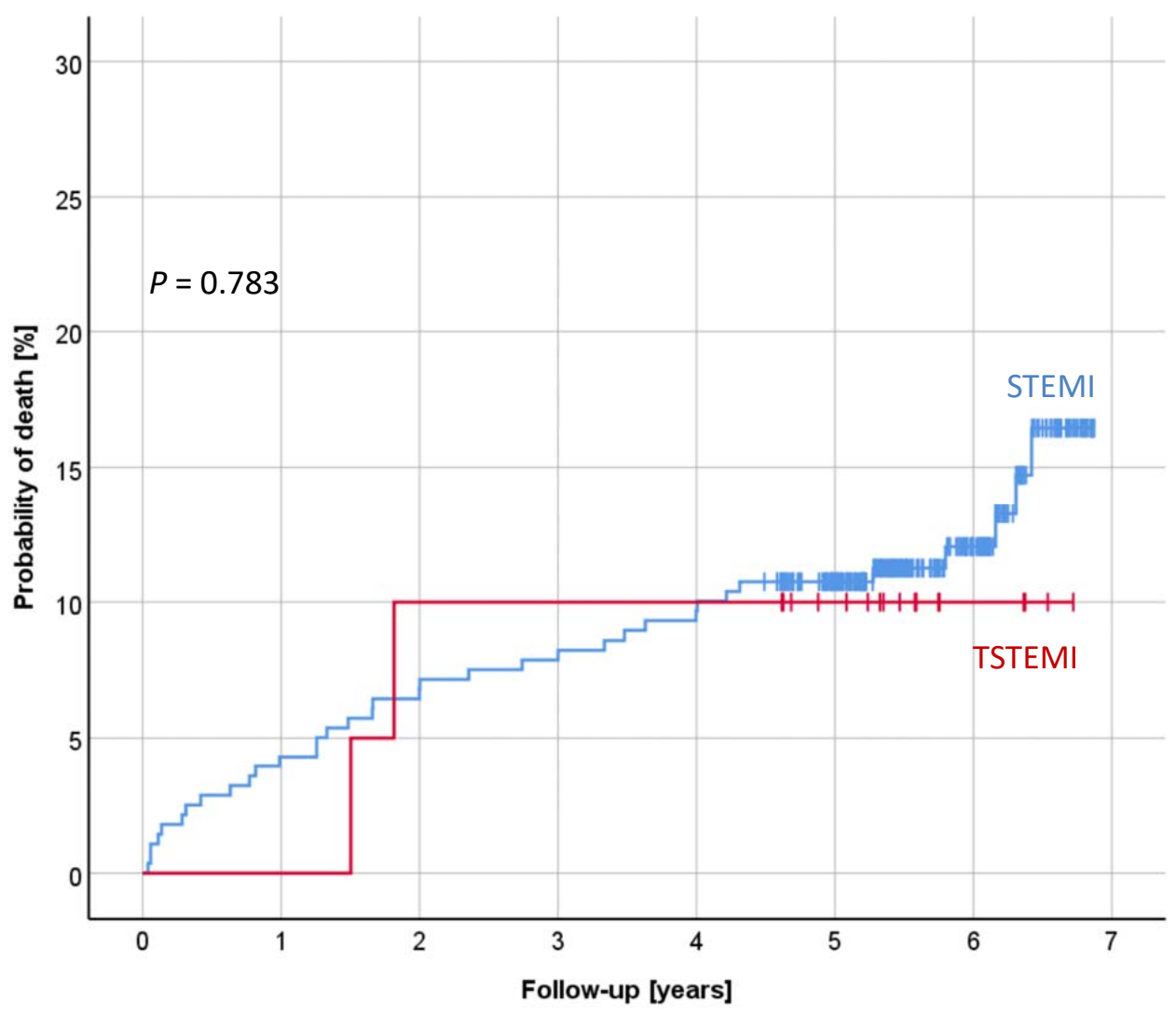

Fig. 1. Kaplan-Meier analysis of probabilities of death in TSTEMI (red line) and STEMI (blue line) patients. Crosses of the survival curves indicate censored cases.



Fig. 2. Kaplan-Meier analysis of probabilities of death in patients with a pre-PPCI TIMI flow grade 0,1 , and 2 (red line) and those with pre-PPCI TIMI flow grade 3 (blue line). Crosses of the survival curves indicate censored cases. 
The ST segment elevation is a valuable indicator of ongoing myocardial ischemia and a prognostic marker ${ }^{9}$. In the thrombolysis era studies, resolution of the ST segment elevation above $70 \%$ was defined as a complete, and this finding was associated with IRA patency due to the drug-induced or spontaneous reperfusion ${ }^{11,19}$. In patients with complete resolution of ST-segment elevation, there were minor infarct size, higher LVEF and lower mortality compared to patients with only partial or no ST-segment resolution. Moreover, absence of ST-segment resolution was the most powerful independent predictor of early post-MI mortality ${ }^{11}$.

In the contemporary PPCI era, an early resolution of ST segment in STEMI patients is still a positive prognostic marker. Patients with complete ST resolution (cSTR) prior to PPCI defined as $\geq 70 \%$ ST resolution or no residual significant ST elevations, have lesser infarct-related myocardial injuries and better prognosis in comparison to patients with persistent ST elevations ${ }^{20-22}$. In a study of 933 STEMI patients, cSTR before PPCI was observed in $24 \%$. These patients showed higher incidence of TIMI flow grade $2 / 3$ before intervention (64\% vs $24 \%$ ) and smaller infarct sizes (6\% vs $11 \%)$ compared to patients with ST elevations present before PPCI (ref. ${ }^{20}$ ). These data are consistent with our observation. In our study group, TSTEMI patients had more preserved LVEF and lower biomarker levels compared to STEMI patients.

However, despite fSTR, occluded IRA was found in $25 \%$ of our TSTEMI patients and pre-PPCI TIMI flow grade 3 was noted only in $9(45 \%)$ of these patients. The incidence of our TSTEMI patients was almost identical to that of the recent registry analyse ${ }^{23}$. Occluded IRA despite fSTR was also common in other studies. In the post-hoc subgroup analysis of the ELISA-3 Trial, which investigated the TSTEMI incidence and characteristics of patients with high-risk non-STE acute coronary syndrome, occluded IRA was found in $12.8 \%$ of TSTEMI patients ${ }^{24}$. The mechanism of fSTR despite occluded IRA is not clear. Possible explanations include adequate collateral flow, both by visible epicardial vessels and invisible small overlay ${ }^{20}$. Other explanation based on in vitro experiments assumes that in some cases, fSTR does not indicate coronary reperfusion. In experiments with isolated pig hearts, decreasing extracellular concentrations of potassium at the edges of ischemic tissue led to the normalization of T-Q depression (and thus ST elevation) during acute ischemia ${ }^{25}$. In an experiment with isolated strips of toad myocardial tissue, new gap junctions were formed during ischemia, alleviating myocardial damage. This might explain the regression of ST segment elevations even in patients who did not undergo reperfusion therapy ${ }^{26}$.

Chest pain is another valuable marker of persistent myocardial ischemia. Nevertheless, as postulated in the present guidelines ${ }^{1}$ all patients in our study received intravenous opioids for pain relief. We thus cannot present any relevant details on the presence or absence of pain as the marker of ongoing myocardial ischemia prior to the catheterization.
The timing of invasive treatment in MI patients with STEMI and non-ST-segment elevation MI infarction (NSTEMI) needs to adhere to the guidelines ${ }^{1,27}$. While in STEMI patients, immediate invasive strategy with PPCI is generally recommended ${ }^{1,28}$, timing of intervention in NSTEMI patients depends on patient's risk profile ${ }^{29,30}$. In very high risk patients, immediate invasive approach is indicated, whereas early invasive strategy $(<24 \mathrm{~h})$ and invasive strategy $(<72 \mathrm{~h})$ are indicated in high risk patients and in intermediate risk patients, respectively ${ }^{31}$. However, the guidelines do not specify any optimal time of invasive treatment of TSTEMI patients. A possible delayed approach is based on the assumption that in TSTEMI patients, there is no ongoing ischemia and that a time delay to PCI may allow ruptured plaque stabilization and thrombus load reduction. The delayed approach was also proposed to lower the incidence of procedural-related complications such as slow or no-reflow phenomenon and to subsequently reduce the infarct size ${ }^{32}$. In 78 STEMI patients with complete ST-segment resolution and pre-PCI TIMI flow grade 3 in IRA, peak CK levels were reported to be significantly lower in the delayed PCI group (24h) compared to the immediate PCI group ${ }^{33}$. Nevertheless, this study was conducted retrospectively, and treatment assignment was not randomised. In the TRANSIENT trial, 142 patients were prospectively randomized to an immediate $(0.3 \mathrm{~h}$ interquartile range $0.2-0.7 \mathrm{~h})$ or a delayed (22.7 h, interquartile range 18.2-27.3) PCI. The overall infarct size measured by magnetic resonance imaging and short-term major adverse cardiac events were not different between the groups. Interestingly, three patients (2.1\%) had occluded IRA despite fSTR (ref. ${ }^{34}$ ).

In our study, catheterization was, by protocol, performed with the shortest possible delay irrespective of the ST-elevation presence or absence. We believe that this approach benefitted particularly those patients with occluded IRA who suffered from ongoing ischemia. Timely performed successful PPCI with early reperfusion minimalized the ongoing ischemia duration and, as seen in our data, resulted in excellent clinical outcomes. The overall long-term mortality was low and did not differ between study groups. A similar result, albeit based on much shorter follow-up, was recently reported based on registry analyses ${ }^{35}$. Nevertheless, not surprisingly, patients with pre-PPCI TIMI flow grade 3 showed a strong trend towards better survival which demonstrated the clinical difference between NSTEMI and a complete coronary flow restoration.

Several important limitations of this study need to be recognized. This is a single centre experience and the number of investigated patients is relatively small. Nevertheless, compared to the existing literature, we were able to extend the study follow-up considerably. While we were able to obtain accurate all-cause mortality data from nationwide registries, we are unable to distinguish cardiovascular and non-cardiovascular causes of deaths. The pre-admission and admission ECGs were not stored electronically, and we are unable to measure other ECG-based risk indicators (e.g. the spatial QRS-T angle). Finally, we 
have no data allowing us to comment on the possibility that in some patients whom we diagnosed as TSTEMI, ST segment changes due to IRA re-occlusion might have re-appeared during the short time between the ECG recording on catheterization laboratory admission and the first contrast injection to IRA. Nevertheless, such cases would only reinforce our conclusions.

\section{CONCLUSION}

The rate of patients with TSTEMI is relatively low $(6.7 \%)$. Immediate treatment with primary PCI in these patients is safe and strongly supported by a relatively high incidence of occluded IRA among these patients.

Acknowledgment: This work was supported by the Ministry of Health of the Czech Republic - conceptual development of research organisation (FNBr, 65269705; funding was given to University Hospital Brno).

Author contributions: LK: ECG analyses, follow-up of patients, manuscript preparation; MM: ECG analyses, follow-up of patients; TN: study concept, ECG analyses, manuscript preparation; JP, TO: manuscript preparation; JK: study electronic database, ECG analyses; MH: ECG analyses, follow-up of patients; MP: study enrolment; JJ: study electronic database, statistical analyses; MM: study concept, statistical analyses, manuscript preparation; PK: study concept, study and project supervision, manuscript preparation.

Conflict of interest statement: The authors declare that the research was conducted in the absence of any commercial or financial relationships that could be construed as a potential conflict of interest.

Contribution to the Field Statement: Patients with transient ST-elevation myocardial infarction (TSTEMI) are at clinical risk of further cardiovascular complications. If the electrocardiogram becomes completely normal in term of ischemia diagnosis (i.e. if an isoelectric ST segment shows full ST-segment resolution) within a short period of time, the therapeutic strategy might be difficult to optimize. In these patients, there is a risk of delayed indication for invasive coronary angiography and of mechanical reperfusion with primary coronary intervention which might still be needed. Several publications deal with the issue of TSTEMI patients with conflicting results and mixed groups of patients including both STEMI and non-STEMI population. In our paper, we show the need for emergent invasive approach in all STEMI patients, irrespective of possible ST segment restoration (TSTEMI) prior to the primary PCI. This strategy is safe, highly effective and in a relatively high proportion of TSTEMI patients with occluded infarct-related artery also clinically necessary. In addition, we describe a relatively long-term clinical followup of the whole cohort of 300 STEMI patients.

\section{REFERENCES}

1. Ibanez B, James S, Agewall S, Antunes MJ, Bucciarelli-Ducci C, Bueno H, Caforio ALP, Crea F, Goudevenos JA, Halvorsen S, Hindricks G, Kastrati A, Lenzen MJ, Prescott E, Roffi M, Valgimigli M, Varenhorst C, Vranckx P, Widimský P; ESC Scientific Document Group. 2017 ESC Guidelines for the management of acute myocardial infarction in patients presenting with ST-segment elevation The Task Force for the management of acute myocardial infarction in patients presenting with ST-segment elevation of the European Society of Cardiology (ESC). Eur Heart J 2018;39:119-77. doi:10.1093/eurheartj/ehx393

2. Zijlstra F, de Boer MJ, Hoorntje J, Reiffers S, Reiber J, Suryapranata $\mathrm{H}$. A Comparison of immediate coronary angioplasty with intravenous streptokinase in acute myocardial infarction. N Engl J Med 1993;328:680-84. doi:10.1056/NEJM199303113281002

3. Widimský P. Long distance transport for primary angioplasty vs immediate thrombolysis in acute myocardial infarction Final results of the randomized national multicentre trial_-PRAGUE-2. Eur Heart J 2003;24:94-104. doi:10.1016/S0195-668X(02)00468-2

4. O'Neill W, Timmis GC, Bourdillon PD, Lai P, Ganghadarhan V, Walton J, Ramos R, Laufer N, Gordon S, Schork MA, Pitt B. A prospective randomized clinical trial of intracoronary streptokinase versus coronary angioplasty for acute myocardial Infarction. N Engl J Med 1986;314:812-18. doi:10.1056/NEJM198603273141303

5. Grines CL, Browne KF, Marco J, Rothbaum D, Stone GW, O'Keefe J, Overlie P, Donohue B, Chelliah N, Timmis GC, Vlietstra RE, Strzelecki M, Puchrowicz-Ochocki S, O'Neill WW, for the Primary Angioplasty in Myocardial Infarction Study Group. A Comparison of immediate angioplasty with thrombolytic therapy for acute myocardial infarction. N Engl J Med 1993;328:673-79. doi:10.1056/ NEJM199303113281001

6. Andersen HR, Nielsen TT, Rasmussen K, Thuesen L, Kelbaek H, Thayssen P, Abildgaard U, Pedersen F, Madsen JK, Grande P, Villadsen AB, Krusell LR, Haghfelt T, Lomholt P, Husted SE, Vigholt E, Kjaergard HK, Mortensen LS; DANAMI-2 Investigators. A comparison of coronary angioplasty with fibrinolytic therapy in acute myocardial infarction. N Engl J Med 2003;349:733-42. doi:10.1056/NEJMoa025142

7. Ellis SG, Debowey D, Bates ER, Topol EJ. Treatment of recurrent ischemia after thrombolysis and successful reperfusion for acute myocardial infarction: effect on in-hospital mortality and left ventricular function. J Am Coll Cardiol 1991;17:752-57. doi:10.1016/ s0735-1097(10)80195-0

8. De Luca G, Maas AC, van 't Hof AW, Ottervanger JP, Hoorntje JC, Gosselink AT, Dambrink JH, de Boer MJ, Suryapranata H. Impact of ST-segment depression resolution on mortality after successful mechanical reperfusion in patients with ST-segment elevation acute myocardial infarction. Am J Cardiol 2005;95:234-36. doi:10.1016/j. amjcard.2004.09.008

9. Brodie BR, Stuckey TD, Hansen C, VerSteeg DS, Muncy DB, Moore S, Gupta N, Downey WE. Relation between electrocardiographic ST-segment resolution and early and late outcomes after primary percutaneous coronary intervention for acute myocardial infarction. Am J Cardiol 2005;95:343-48. doi:10.1016/j.amjcard.2004.09.031

10. Matetzky S, Novikov M, Gruberg L, Freimark D, Feinberg M, Elian D, Novikov I, Di Segni E, Agranat O, Har-Zahav Y, Rabinowitz B, Kaplinsky $\mathrm{E}, \mathrm{Hod} \mathrm{H}$. The significance of persistent ST elevation versus early resolution of ST segment elevation after primary PTCA. J Am Coll Cardiol 1999;34:1932-38. doi:10.1016/S0735-1097(99)00466-0

11. Schröder R, Dissmann R, Brüggemann $T$, Wegscheider $K$, Linderer T, Tebbe U, Neuhaus KL. Extent of early ST segment elevation resolution: a simple but strong predictor of outcome in patients with acute myocardial infarction. J Am Coll Cardiol 1994;24:384-91. doi:10.1016/0735-1097(94)90292-5

12. van't Hof AW, Liem A, de Boer M-J, Zijlstra F. Clinical value of 12-lead electrocardiogram after successful reperfusion therapy for acute myocardial infarction. The Lancet 1997;350:615-19. doi:10.1016/ S0140-6736(96)07120-6

13. Fesmire FM, Bardoner JB. ST-segment instability preceding simultaneous cardiac arrest and $\mathrm{AMI}$ in a patient undergoing continuous 12-lead ECG monitoring. Am J Emerg Med 1994;12:69-76. doi:10.1016/0735-6757(94)90204-6

14. Meisel SR, Dagan Y, Blondheim DS, Dacca S, Shochat M, Kazatsker M, Asif A, Frimerman A, Shotan A. Transient ST-elevation myocardial infarction: clinical course with intense medical therapy and early 
invasive approach, and comparison with persistent ST-elevation myocardial infarction. Am Heart J 2008;155:848-54. doi:10.1016/j. ahj.2007.12.010

15. Steg PG, James SK, Atar D, Badano LP, Lundqvist CB, Borger MA, Di Mario C, Dickstein K, Ducrocq G, Fernandez-Aviles F, Gershlick AH, Giannuzzi P, Halvorsen S, Huber K, Juni P, Kastrati A, Knuuti J, Lenzen MJ, Mahaffey KW, Valgimigli M, van 't Hof A, Widimsky P, Zahger D. ESC Guidelines for the management of acute myocardial infarction in patients presenting with ST-segment elevation. Eur Heart J 2012;33:2569-2619. doi:10.1093/eurheartj/ehs215

16. Chesebro JH, Knatterud G, Roberts R, Borer J, Cohen LS, Dalen J, Dalen J, Dodge HT, Francis CK, Hillis D, Ludbrook P. Thrombolysis in Myocardial Infarction (TIMI) Trial, Phase I: A comparison between intravenous tissue plasminogen activator and intravenous streptokinase. Clinical findings through hospital discharge. Circulation 1987;76:142-54. doi:10.1161/01.CIR.76.1.142

17. Killip T 3rd, Kimball JT. Treatment of myocardial infarction in a coronary care unit. A two year experience with 250 patients. Am J Cardio 1967;20:457-64. doi: 10.1016/0002-9149(67)90023-9

18. Thygesen K, Alpert JS, Jaffe AS, Chaitman BR, Bax JJ, Morrow DA, White HD. Executive Group on behalf of the Joint European Society of Cardiology (ESC)/American College of Cardiology (ACC)/ American Heart Association (AHA)/World Heart Federation (WHF) Task Force for the Universal Definition of Myocardial Infarction. Fourth Universal Definition of Myocardial Infarction (2018). J Am Coll Cardiol 2018;72:2231-64. doi:10.1016/j.jacc.2018.08.1038

19. de Lemos JA, Antman EM, Giugliano RP, McCabe CH, Murphy SA, Van de Werf F, Gibson CM, Braunwald E. St-segment resolution and infarct-related artery patency and flow after thrombolytic therapy. Am J Cardiol 2000;85:299-304. doi:10.1016/S0002-9149(99)00736-5

20. Lønborg J, Kelbæk H, Holmvang L, Helqvist S, Vejlstrup N, Jørgensen E, Saunamäki K, Dridi NP, Kløvgaard L, Kaltoft A, Bøtker HE, Lassen JF, Clemmensen P, Terkelsen CJ, Engstrøm T. Comparison of outcome of patients with st-segment elevation myocardial infarction and complete versus incomplete ST-resolution before primary percutaneous coronary intervention. Am J Cardiol 2016;117:1735-40. doi:10.1016/j. amjcard.2016.03.009

21. Terkelsen CJ, Nørgaard BL, Lassen JF, Poulsen SH, Gerdes JC, Sloth E, Gøtzsche LB-H, Rømer FK, Thuesen L, Nielsen TT, Andersen HR. Potential significance of spontaneous and interventional ST-changes in patients transferred for primary percutaneous coronary intervention: observations from the ST-MONitoring in Acute Myocardial Infarction study (The MONAMI study). Eur Heart J 2006;27:267-75. doi:10.1093/eurheartj/ehi606

22. Terkelsen CJ, Kaltoft AK, Nørgaard BL, Bøttcher M, Lassen JF, Clausen K, Nielsen SS, Thuesen L, Nielsen TT, Bøtker HE, Andersen HR. ST changes before and during primary percutaneous coronary intervention predict final infarct size in patients with ST elevation myocardial infarction. J Electrocardiol 2009;42:64-72. doi:10.1016/j. jelectrocard.2008.08.038

23. Blondheim DS, Kleiner-Shochat $M$, Asif $A$, Kazatsker $M$, Frimerman A, Abu-Fanne R, Neiman E, Barel M, Levy Y, Amsalem N, Shotan A, Meisel SR. Characteristics, Management, and Outcome of Transient ST-elevation Versus Persistent ST-elevation and Non-ST-elevation Myocardial Infarction. Am J Cardiol 2018;121:1449-55. doi: 10.1016/j. amjcard.2018.02.029.

24. Badings EA, Remkes WS, The SHK, Dambrink J-HE, Tjeerdsma G, Rasoul S, Timmer JR, van der Wielen ML, Lok DJ, Hermanides R, van Wijngaarden J, Suryapranata $H$, van 't Hof AW. Early or late intervention in patients with transient ST-segment elevation acute coronary syndrome: Subgroup analysis of the ELISA-3 trial. Catheter Cardiovasc Interv 2016;88:755-64. doi:10.1002/ccd.26719

25. Coronel R, Fiolet JW, Wilms-Schopman FJ, Schaapherder AF, Johnson TA, Gettes LS, Janse MJ. Distribution of extracellular potassium and its relation to electrophysiologic changes during acute myocardial ischemia in the isolated perfused porcine heart. Circulation 1988;77:1125-38. doi:10.1161/01.cir.77.5.1125
26. de Mello WC, Motta GE, Chapeau M. A study on the healing-over of myocardial cells of toads. Circ Res 1969;24:475-87. doi:10.1161/01. res.24.3.475

27. Collet JP, Thiele H, Barbato E, Barthélémy O, Bauersachs J, Bhatt DL, Dendale P, Dorobantu M, Edvardsen T, Folliguet T, Gale CP, Gilard M, Jobs A, Jüni P, Lambrinou E, Lewis BS, Mehilli J, Meliga E, Merkely B, Mueller C, Roffi M, Rutten FH, Sibbing D, Siontis GCM. 2020 ESC Guidelines for the management of acute coronary syndromes in patients presenting without persistent ST-segment elevation. Eur Heart J 2020; in press:ehaa575. doi: 10.1093/eurheartj/ehaa575

28. Fabris E, Arrigoni P, Falco L, Barbati G, Stolfo D, Peratoner A, Vitrella G, Rakar S, Perkan A, Sinagra G. Impact of patient delay in a modern real world STEMI network. Am J Emerg Med 2020;38:1195-98. doi: 10.1016/j.ajem.2020.02.028

29. Janssens GN, van der Hoeven NW, Lemkes JS, Everaars $H$, van de Ven PM, Marques KMJ, Nap A, van Leeuwen MAH, Appelman Y, Knaapen P, Verouden NJW, Allaart CP, Brinckman SL, Saraber CE, Plomp KJ, Timmer JR, Kedhi E, Hermanides RS, Meuwissen M, Schaap J, van der Weerdt AP, van Rossum AC, Nijveldt R, van Royen N. 1-year outcomes of delayed versus immediate intervention in patients with transient ST-segment elevation myocardial infarction. JACC Cardiovasc Interv 2019;12:2272-82. doi: 10.1016/j.jcin.2019.07.018

30. Lemkes JS, Janssens GN, van der Hoeven NW, van de Ven PM, Marques KMJ, Nap A, van Leeuwen MAH, Appelman YEA, Knaapen P, Verouden NJW, Allaart CP, Brinckman SL, Saraber CE, Plomp KJ, Timmer JR, Kedhi E, Hermanides RS, Meuwissen M, Schaap J, van der Weerdt AP, van Rossum AC, Nijveldt R, van Royen N. Timing of revascularization in patients with transient ST-segment elevation myocardial infarction: a randomized clinical trial. Eur Heart J 2019;40:283-91. doi: 10.1093/eurheartj/ehy651

31. Roffi M, Patrono C, Collet J-P, Mueller C, Valgimigli M, Andreotti F, Bax JJ, Borger MA, Brotons C, Chew DP, Gencer B, Hasenfuss G, Kjeldsen K, Lancellotti P, Landmesser U, Mehilli J, Mukherjee D, Storey RF, Windecker S. 2015 ESC Guidelines for the management of acute coronary syndromes in patients presenting without persistent STsegment elevation. Eur Heart J 2016;37:267-315. doi:10.1093/eurheartj/ehv320

32. Carrick D, Oldroyd KG, McEntegart M, Haig C, Petrie MC, Eteiba $H$, Hood S, Owens C, Watkins S, Layland J, Lindsay M, Peat E, Rae A, Behan M, Sood A, Hillis WS, Mordi I, Mahrous A, Ahmed N, Wilson R, Lasalle L, Généreux P, Ford I, Berry C.. A Randomized Trial of Deferred Stenting Versus Immediate Stenting to Prevent No- or Slow-Reflow in Acute ST-Segment Elevation Myocardial Infarction (DEFER-STEMI). J Am Coll Cardiol 2014;63:2088-98. doi:10.1016/j.jacc.2014.02.530

33. Meneveau N, Séronde MF, Descotes-Genon V, Dutheil J, Chopard R, Ecarnot F, Briand F, Bernard Y, Schiele F, Bassand JP. Immediate versus delayed angioplasty in infarct-related arteries with TIMI III flow and ST segment recovery: a matched comparison in acute myocardial infarction patients. Clin Res Cardiol 2009;98:257-64. doi:10.1007/ s00392-009-0756-z

34. Lemkes JS, Janssens GN, van der Hoeven NW, van de Ven PM, Marques KMJ, Nap A, van Leeuwen MAH, Appelman YEA, Knaapen P, Verouden NJW, Allaart CP, Brinckman SL, Saraber CE, Plomp KJ, Timmer JR, Kedhi E, Hermanides RS, Meuwissen M, Schaap J, van der Weerdt AP, van Rossum AC, Nijveldt R, van Royen N. Timing of revascularization in patients with transient ST-segment elevation myocardial infarction: a randomized clinical trial. Eur Heart J 2019;40:283-91. doi:10.1093/eurheartj/ehy651

35. Almendro-Delia M, Seoane García T, Villar Calle P, García González N, Lorenzo López B, Cortés FJ, García Del Río M, Ruiz García MDP, Hidalgo Urbano RJ, García-Rubira JC. Prevalence and clinical significance of totally occluded infarct-related arteries in patients with non-ST-segment elevation acute coronary syndromes. Int J Cardiol 2021;324:1-7. doi:10.1016/j.ijcard.2020.09.040 